\title{
VIVÊNCIAS FAMILIARES DE ADOLESCENTES USUÁRIOS DE DROGAS
}

\author{
Rafael Rodrigo da Silva Pimentel \\ Thaís Fukunishi Soares* \\ Adriana Danmvolf Ribas * \\ Márcia Glaciela da Cruz Scardoellit*
}

RESUMO: 0 objetivo deste estudo foi compreender a vivência da família com adolescente usuário de álcool e substâncias psicoativas. Pesquisa descritiva de abordagem qualitativa realizada no período de julho a setembro de 2015. Participaram deste estudo, cinco familiares de usuários de crack e outras substâncias psicoativas. A coleta de dados foi realizada por meio de entrevistas com questionário semiestruturados contendo questões abertas e fechadas. Para análise dos dados utilizou-se a técnica de análise de conteúdo modalidade temática proposta por Minayo (2007). Os resultados demonstraram os prejuízos afetivos que 0 uso de drogas pelo adolescente traz para seus familiares, expressados por sentimentos de raiva, angustia, medo, preocupação. Além da sobrecarga de trabalho e cuidados expressa pelo adolescente. Diante disso, 0 estudo mostrou a necessidade de uma atenção voltada para o familiar do usuário de drogas.

PALAVRAS-CHAVE: Família; Adolescentes; Drogas; Álcool; Crack.

\section{FAMILIAL EXPERIENCES IN ADOLESCENT DRUG USERS}

ABSTRACT: The familial experience with adolescent alcohol and drug users is investigated. Current descriptive and qualitative research was undertaken between July and September 2015. Five family members of crack and other psychoactive drugs users participated. Data were collected through half-structured interviews with open and closed questions. Content analysis, theme mode, proposed by Minayo (2007) was employed. Results reveal the affection liabilities to kin, expressed anger, angst, fear and concern, besides the overload of work and care. Current analysis demonstrated the need for more attention to family members of drug users.

KEYWORDS: Family; Adolescents; Drugs; Alcohol; Crack.

\section{INTRODUÇÃO}

A família é 0 fator mais importante no processo de desenvolvimento dos seus entes queridos, com ela temos os primeiros contatos emocionais, comunicacionais e afetivos e a partir dela temos nossas primeiras relações sociais. 0 contexto familiar é considerado como um dos grandes fatores de risco ou proteção no envolvimento dos seus membros com 0 mundo das drogas (ZACHARIAS et al., 2011).

0 ambiente familiar apresenta vários elementos que podem atuar como um fator facilitador ao uso do crack, álcool, maconha e outras substâncias psicoativas sendo estes, a deficiência de suporte dos pais; a cultura familiar; 0 uso de drogas por algum familiar próximo; a presença de conflitos familiares, e a desinformação e desconhecimento familiar sobre 0 uso e abuso das drogas (SELEGHIM; OLIVEIRA, 2013).

Em estudo realizado por Brusamarello et al. (2010), evidenciou-se que os pais relatam que durante o processo de educar os filhos, há grande insegurança e dificuldade, pois há necessidade de fatores como

\footnotetext{
"Discentes do curso de Enfermagem do Centro Universitário de Maringá (UNICESUMAR), Maringá (PR), Brasil.

** Mestre em Ciências da Saúde, Docente no curso de Medicina do Centro Universitário de Maringá (UNICESUMAR) Maringá (PR), Brasil.

*** Mestre em Enfermagem, Docente no curso de Centro Universitário de Maringá (UNICESUMAR) Maringá (PR), Brasil; E-mail: grajcruz@gmail.com.
} 
tempo, companhia, paciência, amor e diálogo contínuo, já que os pais passam maior tempo em seus locais de trabalho. Isto possibilita que 0 adolescente permaneça um longo período sozinho, podendo se aproximar de pessoas que poderão influenciá-los ao uso das drogas.

De acordo com Zacharias et al. (2011), é importante entender que a drogadição apresenta muitos fatores orgânicos, psicológicos, socioculturais, familiares, espirituais e outros que devem ser reconhecidos para melhor assistência à família e ao adolescente.

Para Santos et al. (2011), os motivos que levam os adolescentes a buscar o "mundo das drogas" é a curiosidade por algo desconhecido juntamente com a falta de informação sobre as drogas que quase sempre são provenientes de pessoas próximas e confiáveis para 0 adolescente. Estas fontes são representadas pela própria família e por colegas de escolas, que se constitui como um fator de risco para o uso do crack, álcool e outras substâncias psicoativas.

Segundo Canavez, Alves e Canavez (2010), os fatores de risco que mais se destacam no momento em que 0 adolescente decide buscar o "mundo das drogas" estão ligados à mudança no afeto de seus familiares, à vitimização por violência doméstica, à personalidade depressiva, à baixa autoestima que é um dos fatores de vulnerabilidade para que os adolescentes corram maior risco de se tornarem usuários do crack, álcool e outras substâncias psicoativas.

As maiores causas da dependência as drogas na adolescência é a facilidade de encontrar as substâncias pela falta de fiscalização em bares e lanchonetes, 0 uso de drogas por familiares, os conflitos; 0 comportamento problemático (agressivo, alienado, rebelde) 0 baixo aproveitamento escolar que leva à vulnerabilidade ao uso das drogas (MARQUES; CRUZ, 2000).

Cenário um hospital de natureza estadual, localizado na zona norte da cidade de Teresina, Piauí. 0 referido hospital realiza internação como tratamento de intoxicação aguda em usuários de álcool, crack e outras drogas, tratamento da síndrome de abstinência do álcool e outras drogas
Em estudo realizado por Carvalho, Oliveira e Martins (2014), em um hospital estatual localizado no Piauí, que realiza tratamento de intoxicação aguda em usuários de crack, álcool e outras substâncias psicoativas, observou por meio de relatos de mães a existência de uma mudança de sentimentos durante a convivência com seu filho usuário de drogas, e que esta mudança oscila entre a vontade de ajudar, de dar uma proteção para seu filho e esperança de melhora, mas que logo se transforma em desesperança, sensação de caso perdido, podendo levar a um sentimento de rejeição de seu filho, no qual o sofrimento é tão intenso que interfere no amor, tornando-a capaz de desejar a morte do seu próprio filho.

Esses sentimentos são justificados pelas dificuldades vivenciadas por essas mães em relação ao acesso e ao tratamento, à condição de dependência do crack enfrentada pelos filhos que, em muitos casos, não contam com 0 apoio nem mesmo da família, sendo estas, refletidas no tratamento, na dificuldade de controle emocional da situação, permitindo assim que esse usuário continue no mundo das drogas (CARVALHO; OLIVEIRA; MARTINS, 2014).

Diante ao exposto, faz-se necessário oferecer maior atenção para a família no momento em que buscarem pelos serviços de saúde, fornecendo apoio e proporcionando melhor qualidade de vida, pois em sua maioria estão sobrecarregadas de sentimentos e dificuldades que não são aliviados apenas com 0 acesso ao serviço de saúde (CARVALHO; OLIVEIRA; MARTINS, 2014).

0 estudo de Reis e Moreira (2012) evidenciou que a convivência familiar com um membro dependente químico é extremamente complexa, gerando uma sobrecarga para toda família, mais precisamente sobre aqueles responsáveis pelo cuidado direto. Embora exista toda essa sobrecarga, a família nunca deixa de amar o seu ente querido dependente químico e sempre busca 0 melhor para que ele encontre 0 caminho longe das drogas.

Diante deste contexto, este estudo teve como objetivo compreender a vivência da família com adolescente usuário de crack e outras substâncias psicoativa. 


\section{METODOLOGIA}

Trata-se de uma pesquisa exploratória e descritiva, com abordagem qualitativa.

Os sujeitos da pesquisa foram cinco familiares de adolescentes usuários de crack outras substâncias psicoativas que são acompanhados pelo Centro de Atendimento Psicossocial infanto juvenil (CAPSi) e Centro de atendimento Psicossocial Álcool e Drogas (CAPSad) de Maringá-Pr.

0 CAPSi destina-se a atender crianças e adolescentes, entre 03 e 17 anos 11 meses e 29 dias, com comprometimentos psicossociais severos e persistentes, residentes no município de Maringá e seus distritos de Floriano e de Iguatemi. Incluem-se nesta categoria os portadores de autismo, psicoses, usuário de álcool e outras drogas, neuroses graves $\mathrm{e}$ todos aqueles cujo comprometimento causa prejuízos acentuados em vários aspectos da rotina de vida da criança/adolescente (familiar, social, afetivo, escolar, dentre outros) (BRASIL, 2004).

0 CAPSad é a uma unidade de saúde especializada em atender os dependentes de álcool, crack e outras drogas, dentro das diretrizes determinadas pelo Ministério da Saúde, que tem por base 0 tratamento do paciente em liberdade, buscando sua reinserção social. Desta forma, 0 CAPSad oferece atendimento diário a pacientes que fazem uso prejudicial de álcool e outras substâncias psicoativas, permitindo o planejamento terapêutico dentro de uma perspectiva individualizada de evolução contínua (BRASIL, 2004).

Ainda dentro do atendimento às necessidades dos dependentes químicos, as famílias também são acompanhadas semanalmente pelos psicólogos, por meio de um grupo para atendimento, em que são esclarecidas dúvidas, anseios e é oferecido 0 suporte que a família necessita (BRASIL, 2004).

0 CAPSad possui como público específico os adultos, mas também podem atender crianças e adolescentes, desde que observadas às orientações do Estatuto da Criança e do Adolescente (ECA) (BRASIL, 2004). Para identificação e reconhecimento dos adolescentes atendidos pelo CAPSi e CAPSad procurou-se seguir à orientação do ECA que considera a criança 0 cidadão que tem até 12 anos incompletos. Aqueles com idade entre 12 e 18 anos são adolescentes (BRASIL, 1990).

Face ao exposto, para o desenvolvimento da pesquisa foi solicitado autorização ao Centro de Formação e Capacitação Permanente dos trabalhadores da Saúde (CECAPS). Na sequência, após a autorização do local, o projeto foi encaminhado ao Comitê de Ética e Pesquisa (CEP) do UniCesumar, para apreciação e emissão do parecer $\mathrm{n}^{\circ}$ 1.157.121.

Após está aprovação e autorização, foram selecionados os pacientes cadastrados e acompanhados pela instituição, no qual foi realizado um contato por telefone, para agendar a entrevista, esclarecer objetivos do estudo, bem como sua importância e a forma de participação.

A coleta de dados foi realizada no período de julho a setembro de 2015 e foi realizada por meio de entrevista através de questionário semiestruturado, contendo questões abertas e fechadas, após a assinatura do Termo de Consentimento Livre Esclarecido (TCLE), que foi gravada, mediante 0 consentimento, para promover maior fidedignidade de reprodução do pensamento do entrevistado, sendo realizadas no CAPSi para proporcionar ambiente favorável e com segurança aos sujeitos.

$\mathrm{Na}$ posse dos dados, os mesmos foram submetidosà análise de conteúdo, modalidade temática proposta por Minayo (2007) e seguiram as seguintes etapas: a) pré-análise: uma etapa de organização, que corresponde a um período de intuições, mas tem por objetivo sistematizar as ideias iniciais, de maneira a conduzir a um esquema preciso de análise; b) exploração do material: ocorre a transformação dos dados coletados em conteúdos temáticos atrás da codificação das entrevistas, determinando, então, as temáticas a serem discutidas; c) tratamento dos resultados, inferência e interpretação: mediante os dados obtidos anteriormente, utilizam-se inferências e interpretações a partir da fundamentação teórica $e$ dos pressupostos que permeiam a pesquisa. 
Por meio deste processo, as unidades temáticas que emergiram foram: percepção dos familiares quanto ao envolvimento dos filhos com as drogas; mudanças ocorridas no relacionamento e na rotina da família após a descoberta e; sentimentos despertados na família quanto ao usuário.

Assim, no sentido de resguardar suas identidades, as entrevistadas foram identificadas por codinomes (E1, E2 ....E5).

\section{RESULTADO E DISCUSSÃO}

Inicialmente faz-se necessário caracterizar as participantes da pesquisa que foram cinco familiares de cinco adolescentes usuários de substância psicoativas, sendo estas representadas por quatro mães e uma avó, com idade variada entre 38 a 65 anos.

Em relação à escolaridade, três apresentaram ensino fundamental completo, uma ensino médio completo, e uma ensino superior completo. Quanto ao estado civil, encontraram-se várias conformações de união, duas casadas, uma solteira, uma divorciada, e uma em união estável. Já em relação ao número de filhos, três das entrevistadas relataram ter mais de um filho com idade variada entre 19 a 26 anos.

Quanto à religião, quatro são católicas e uma evangélica. Das entrevistadas, três estavam empregadas, sendo destas uma corretora de imóveis, uma cuidadora de idosos, uma doméstica e duas do lar.

A adolescência é um fator importante para 0 desenvolvimento dos indivíduos, a partir desse período que 0 adolescente começa a compreender seus medos, limites e seus potenciais, muitas mudanças acontecem tanto no aspecto físico quanto no emocional. (PINSKY, BESSA, 2004).

0 adolescente está exposto a muitas situações de risco, que aumentam sua vulnerabilidade tanto na área biológica, quanto psíquica e social. Situações de risco essas, a dificuldade para entrar na escola, falhas dos serviços de saúde; violência; uso de drogas; más condições de moradia; pobreza; abandono; falta de estrutura familiar; entrada precoce no mercado de trabalho; exclusão social e barreira cultural; exploração sexual e prostituição; gravidez não desejada e aborto; sexualidade precoce e desprotegida; sofrimento e adoecimento psíquico; instabilidade emocional decorrentes da mudança hormonal da puberdade (PESSALACIA; MENEZES; MASSUIA, 2010).

$A$ adolescência é um período da vida em que 0 adolescente passa por dificuldades para suportar as repetitivas condições de estresse ligadas a ele. Pois nessa idade prevalece uma forte carga de pressão social exigida sobre os jovens, ao deixarem a infância, perdendo a dependência de proteção e cuidados (MATTOS; SILVA, 2004).

A mudança de um estado de dependência total para uma condição de autonomia pessoal precisa ser um processo acompanhado, no qual o jovem tenha total apoio dos pais, educadores ou responsáveis. Assim, ele será capaz de passar pelas dificuldades que ocorrem com idade, de superar e aprender a conviver com suas próprias incertezas e principalmente, de tomar suas próprias decisões de forma responsável, sem que os adultos tenham de decidir tudo por eles (MATTOS; SILVA, 2004).

A família tem papel importante do desenvolvimento do adolescente, pois ela é seu primeiro ponto de referência por ser sua primeira estrutura. Ela também é quem possibilita o contado com 0 mundo externo, tendo grande importância no destino do adolescente (ZACHARIAS et al., 2011).

\subsection{PERCEPÇÃO DOS FAMILIARES QUANTO AO ENVOLVIMENTO DOS FILHOS COM AS DROGAS}

Ao buscar conhecer as situações que levaram os familiares a perceber 0 início do uso de drogas, foi possível observar a existência de alterações de comportamentos tanto antes quanto após a inserção das drogas, que até então não eram presentes na rotina da família.

Nos relatos abaixo, as mudanças comportamentais indicadas pelos familiares foi 0 abandono escolar e a reprovação. 
Ela não estudava quando ela estava fazendo 0 primeiro ano do fundamental, foi quando as coisas começaram a aparecer, as atitudes, as coisas dela começou a ficar muito pesada, [...] ela matava aula, e ela tinha 114 faltas e a escola não deu conta disso, ela passava de ano colando. (E5)

Não queria ir para escola, desistiu um tempo, mas voltou atrás e continua indo, ai assim, ele entrava 7:00 e saia as 10:00. Era 8:30 o horário que ele ia para a sala de aula, então estavam (professores) sempre me ligando. E o E. não vem para a escola? Eu falava, já saiu pra ir aí... Mas ele não chegou ainda, não está na sala de aula. (E4)

Não quer ir para escola está ai fazendo EJA para poder terminar como ele já esta meio atrasado, mas assim é empurradão sabe. (E4)

Ela tinha abandonado a catequese [...] e ela não falava pra ninguém. (E2)

Segundo Alves e Kossobudzky (2002), o consumo de drogas pode causar danos no funcionamento ocupacional e social. Apesar dos danos não estarem claramente definidos em estudos neurológicos, estes causam alterações nas funções cognitivas de memória, formas de pensamento e percepções influenciando na aprendizagem, acarretando em prejuízo no rendimento escolar. Com isso, 0 atraso escolar pode ser visto como uma das consequências sociais pelo uso de drogas. Porém, também as dificuldades quanto ao desempenho escolar, a frustração escolar, ou a insatisfação decorrente de um ensino falho que não traz atrativos, poderiam tornar-se fatores de vulnerabilidade para 0 consumo de drogas nessa faixa etária.

Segundo Tavares, Béria e Lima (2001), a ausência da escola pode ser um dos fatores que inclui ou aproxima ao uso de drogas. Independentemente do que tenha acontecido antes, no entanto, a ausência atual da escola é um marcador de necessidade de intervenção.
Alguns familiares relataram que a agressividade era algo constante no convívio familiar que levaram a desconfiar do envolvimento de seus filhos estarem usando algum tipo de drogas:

Ela era muito teimosa, sabe dava aqueles gritos, aqueles coices machucava a gente, mas nunca me passou pela cabeça que ela usava drogas. (E5)

Percebi que ele foi mudando 0 comportamento [...]. (E1)

Com a família ela é agressiva, com os amigos não é mais tranquila, comigo também um pouco agressiva. Não temos um bom relacionamento. (E3)

Se ele chega alterado, só falar mais alto que ele, ele fica na dele. (E4)

Teve um dia que ela disse que se alguém relasse nela ela ia mandar matar todo mundo [...]. (E5)

Entre os problemas ligados ao consumo excessivo de drogas, além dos fatores relacionados à escolaridade, destacou-se também a presença de comportamentos antissociais, mostrado não apenas por condutas de agressividade na família e fora de casa, assim como episódios de violência doméstica que são um dos motivos que levaram ao internamento, como também da incidência de infrações cometidas pelos adolescentes para aquisição de drogas e envolvimentos com a polícia (ALVES; KOSSOBUDZKY, 2002).

Também foi possível observar que algumas familiares relatam a não aceitação de regras pelo adolescente, refletindo no relacionamento familiar.

Eu falo não e ela vira outra pessoa, ai eu digo para ela daqui a pouco você vai ser de maior ai você vai ver, ela não aceita não, eu já sofri muito com isso, eu sempre fui muito carinhosa com meus filhos, mas também sempre fui sargentona, mas ela sempre teve dificuldade de ouvir um não. (E5) 
Um dia que ela me ligou e eu estava apurada no trabalho eu precisava sair e não conseguia, eu cheia de coisas para resolver, e ela falou que ia posar na casa da amiga dela. Eu falei claro que não. Com isso ela falou mãe você é uma pilantra. Ai eu falei você é uma vagabunda para chamar sua mãe de pilantra. Eu nunca tinha chamado ela por esse nome, eu falei você é uma vagabunda, isso é coisa de drogado, de noiado. $\mathrm{E}$ ela falou que não ia voltar para casa. (E5)

Saia muito né, chegava coleguinha chamava e saia mesmo eu falando não, ele teimava e saia "não, vou ali rapidinho e já volto". (E1)

Mas ele ultimamente não tem me ajudado em casa, nem nas coisas dele, uma bagunça ele não arruma. (E1)

Ele é muito preguiçoso muito desatento, muito relapso, em todos os sentidos então tudo que você vai falar para ele não foi ele, tudo que você fala para ele, ele não aceita. Ele já era assim, depois que começou a usar as drogas piorou, ele já era devagar, mas depois disso piorou completamente. (E4)

Segundo Chenker e Minayo (2003), a forma de criar os filhos é fundamental na construção do indivíduo desde a infância até a adolescência. 0 adolescente que apresenta desordem de conduta e abuso de substâncias possui algumas características durante sua criação: condução insatisfatória da família, criação ausente, disciplina e monitoramento parental inapropriado, irritabilidade dos pais, processos familiares coercitivos. Por outro lado, é papel do familiar proteger a criança dos fatores de risco.

De acordo com Zacharias et al. (2011), a falta de comunicação e o envolvimento afetivo/emocional entre os familiares geram um abuso de autoritarismo, causada por ausência paterna na criação de regras, limites e respeito. Famílias que não abrem espaço para expressar sentimentos, ideias e opiniões, geram verdadeiro vazio familiar.

Em relação ao momento da descoberta do familiar estar usando realmente algum tipo de droga, alguns familiares são pegos de surpresa quando outras pessoas próximas da família denunciam algo diferente com 0 adolescente ou então 0 próprio adolescente acaba se declarando usuário:

Porque ele estava, na assistente social do M. (colégio) e as meninas começaram a perceber que ele estava chegando meio alterado, meio diferente né e me chamaram para conversar, ai eu fui conversar com ele e ele me confessou que, que estava fumando maconha. (E4)

[...] um dia a escola me ligou em 2014, pegaram ele com 1 grama de maconha no bolso, mas já desconfiava. (E1)

Uma pessoa da igreja me ligou dizendo, estou em oração por você, foi ela que me orientou, ela abriu meus olhos falou que tinha coisa errada com minha filha, ela veio e conversou com jeitinho, eu falava só se ela começou a usar agora, porque eu não acreditava. (E5)

0 meu filho mais velho me falou mãe eu tenho medo da $G$. estar usando drogas, eu dizia jamais, sabe assim, pela criação, por tudo. (E5)

De acordo com Zacharias et al. (2011), muitos familiares sentem o receio em lidar com essa situação da drogadição, por ser algo desconhecido e temeroso. Em muitos casos, negam a problemática, precisando que um terceiro faça a função de relator de uma realidade que a família está vivenciando.

Após a descoberta do uso das drogas no contexto familiar, é possível notar nos relatos dos familiares, que eles acreditam que o primeiro contato do adolescente com as drogas foi por influência de amigos de escola, bairro entre outros, refletindo na não aceitação dessas amizades pelos familiares: 
Ela tinha más companhias quando usava drogas, fez amizades com pessoas que eu não gostava e não conseguia gostar, ela nunca foi de sair até hoje não sai sozinha à noite, isso aconteceu no horário da aula, na aula livre, ou saia mais cedo, quando ia fazer um trabalho e não ia. (E2)

Eu falo pra ele como você usa droga, ele fala sempre tem algum que dá, tem uns amigos que intermediam, nunca foi ninguém em casa cobrar sabe, nada assim dele. Quando ele sai ele fala que vai no fulano de tal, mas eu não conheço, onde mora, ele fala mora ali, sempre assim, mora ali, mas não fala mora em tal lugar e filho de fulano de tal, você nunca sabe com quem tá. (E4)

Ele gosta muito de balada vive na rua de bebedeira, drogaiada ele fala que está bem, trabalha, mas 0 dinheiro que ele ganha vai tudo para as baladas dele, é uma tristeza viu. Tem muitos amigos, que vão em casa, muitos moleques procuram por ele. Ele fala assim "to na casa do meu amigo já estou indo embora", as vezes quando ele enfeza ele desliga o celular, eu fico agoniada, ele desliga pra eu não ficar ligando. Mas não sossego em quanto ele não entra para dentro de casa. Toda sexta para sábado ele vai pra balada, eu fico a noite toda praticamente acordada, ele vai em show de funk, ai eu fico dormindo e acordando, dormindo e acordando, até o horário que ele chega, depois que ele chega então eu vou dormir, minha vida é assim, só descanso quando ta todo mundo em casa, ou vejo que eles estão bem, ai eu fico em paz. muito triste viu. (E1)

Segundo Jinez, Souza e Pillon (2009), nessa etapa da adolescência ocorre forte ligação a grupos, é um modo de identificação para a aceitação dos amigos, compartilhando valores comuns e desenvolvendo um modo de cultura particular, junto ao sentimento de invulnerabilidade do adolescente, sentindo-se onipotente, gerando importantes fatores de risco para
0 uso de drogas.

\subsection{MUDANÇAS OCORRIDAS NO RELACIONAMENTO E NA ROTINA DA FAMÍLIA APÓS A DESCOBERTA}

As mudanças que ocorrem com o familiar do adolescente usuário de drogas são bem claras nos depoimentos a seguir. Muitas delas passam por mudanças em suas rotinas, precisando abrir mão de suas vidas para cuidar de seu familiar que precisa de uma atenção integral, deixando de trabalhar, fazer as atividades que costumavam realizar; não conseguem ter descanso físico e emocional, consequente do medo e da preocupação com o futuro do adolescente, gerando grande sobrecarga diária.

Eu deixei de viver, eu fiquei devendo no cartão especial, agora estou pagando as dividas, coisa que vem acumulando não tenho trabalhando direito eu não tenho paz. Eu não trabalhava, um desgaste total, emocional e tudo [...]. (E5)

A gente não sossega, fica atrás dele 0 tempo todo, sabe a gente não desistiu, a gente vai atrás, vai buscar, meu marido traz ele aqui no Caps, fica lá fora esperando terminar, ai leva ele para casa, leva no lar escola para a preparação do emprego. Não tenho lazer não, para falar a verdade não sinto falta disso, o que eu gostaria mesmo e de estar bem nessa parte com eles, se ele estivesse bem, nossa se ele tivesse bem para mim seria tudo, a gente sempre tem esperança dele sair disso, acho que toda, mãe, que no caso eu estou fazendo o papel de mãe dele, crio ele desde pequenininho, toda mãe almeja pelo seu filho, eu queria ver ele bem, bem empregado, trabalhando sabe, com um monte de amigos passeando, com o lazer dele, com 0 salario bom, é isso que a gente espera, com essa vida que ele está levando a gente só pensa o pior né, eu falo para ele só tem dois caminhos, é a cadeia ou a morte, se ele continuar dessa forma, e o que gente vê por ai. (E4) 
Em estudo realizado por Carvalho, Oliveira e Martins (2014), com mães de usuários de drogas, demonstrou-se que muitas delas, passaram por várias transformações, precisando abdicar de suas convicções e interesses em favor dos filhos, como deixar de trabalhar, para dedicarem-se aos filhos, por medo, proteção e receio de futuros agravos familiares.

Muitas mudanças ocorrem também no relacionamento com outros membros da família, pois nem todos os familiares conseguem aguentar as mudanças ocorridas nas rotinas da família, causando conflito familiar, fazendo com que desistam de ajudar no tratamento e no cuidado do adolescente usuário de drogas e muitas vezes ficando contra 0 familiar que mais ajuda 0 adolescente, sendo possível observar nos depoimentos a seguir:

0 irmão do meio não vem mais em casa por causa dela, nem para almoço, quando eles souberam que ela voltou da internação eles ficaram muito revoltados eles falavam porque nos sabemos o que a mamãe passou, 0 que ela fez 0 que ela lutou, eles deram uma ajuda financeira na época, quando eu precisava, quando apurava. (E5)

0 meu filho mais velho vai pouco em casa, e o mais novo, não vai mais em casa por causa dela [...]. (E5)

Eu fico muito chateada, meu marido tá ficando doente, esgotado, sem paciência, ele já está pensando em ir embora de casa, já está numa situação que ele só não foi mesmo embora de casa por mim, porque se não ele já tinha abandonado tudo. (E4)

Para Silva et al. (2012), manter um relacionamento familiar com pessoas usuárias de álcool e outras drogas é muito difícil, com maior relevância quando elas não estão implicadas no processo de tratamento. Quando se fala de dependência química, deve-se partir do princípio de que a recuperação não se limita apenas à suspensão da droga, mas também ao reestabelecimento dos laços sociais e afetivos, como é o caso dos laços familiares.

Os usuários de drogas que possuem uma família sem condições para acompanhar 0 seu tratamento são mais propensos à irritabilidade, possuem pouca participação no serviço, possuem pouca autoestima, com consequentes "recaídas" 0 que dificulta tanto o controle do consumo de drogas, como sua ressocialização (SILVA et al., 2012).

Para Carvalho, Oliveira e Martins (2014), a família é considerada como alicerce necessário para a reinserção social do indivíduo que apresenta dependência e 0 principal instrumento competente para resolver o problema de consumo de droga do filho.

Em um estudo, observou-se que 0 ambiente familiar apresentou vários elementos considerados desfavoráveis que atuaram como elemento facilitador ao uso de drogas de abuso e ao crack como, por exemplo: a deficiência de suporte parental, a cultura familiar do uso de álcool e de outras drogas, os conflitos familiares, a desinformação e 0 desconhecimento familiar sobre o uso do crack, álcool, maconha e outras drogas (SELEGHIM; OLIVEIRA, 2013).

\subsection{SENTIMENTOS DESPERTADOS NA FAMÍLIA QUAN- TO AO USUÁRIO}

Após a descoberta do uso das drogas pelo adolescente, muitos sentimentos são revelados, tornando evidente que 0 familiar que mais sofre com essa descoberta é as mães, que sempre estiveram ao lado de seus filhos, sentimentos esses como a decepção, a angústia e a tristeza, o medo entre outros, foram os que mais estão presentes nos relatos a seguir.

Eu não confio mais nele, ando igual uma louca pela rua atrás dele, quando eu desconfio que ele foi para algum lugar, eu vou, eu vou na escola para ver se ele já entrou na escola. To vivendo a vida dele sabe, me sinto muito angustiada, sobrecarregada, muita tristeza sabe, até falo para ele "meu coração só vive triste" não tenho mais alegria, aquela alegria sabe? 
Não tem mais, não existe mais. Eu espero que ele melhore, e que 0 outro (irmão) tenha a libertação. Eu to muito abalada ultimamente, tenho muito medo de morrer $\mathrm{e}$ deixar essas crianças desse jeito, e 0 que eu peço para Deus todos os dias que ele aumente a minha vida, até pelo menos o mais novo ficar de maior de idade, ele vencer esse mal que está nele, esse é meu sonho, é vencer esse mal e eu saber que eles estão bem, e eu peço para Deus todos os dias para não me colocar em uma cama porque eu sei que vou dar trabalho para minha filha que vai ser a única que vai cuidar de mim eu tenho certeza, eu peço para Deus me dar saúde, mas minha saúde está bastante abalada, eu fico muito tensa. (E1)

Você não confia mais, você não acredita mais, se ele está falando a verdade você está com o pé atrás, quando ele ta na rua eu fico super preocupada, com quem tá, onde tá, 0 que ta fazendo. (E4)

Eu no caso sou muito medrosa me prendia mais, não queria sair de casa, ela saia para a escola ficava muito apreensiva, é bem difícil, faz pouco tempo que comecei a melhorar, isso afetou muito minha vida, deixei de fazer muitas coisas por causa dela. Nossa relação ainda é muito difícil, fico muito nervosa, depois que iniciou 0 tratamento melhorou bastante, mas vamos dizer assim, que é razoável, as vezes é muito bom, depende. (E2)

Segundo Carvalho, Oliveira e Martins (2014), 0 relacionamento entre mãe e filho, após o filho tornarse dependente de drogas, apresenta sentimentos variáveis, ao mesmo tempo em que existe sentimento de piedade, vontade de ajudar, de ser tolerante, de coragem de enfrentar o perigo para libertar seus filhos deste mundo da dependência, também existe o sentimento de insegurança, raiva, desconfiança, desespero, desesperança e dor de ter perdido o filho para a dependência das drogas.
Em outro depoimento pode-se observar que 0 familiar revela um sentimento de vergonha $e$ medo frente à descoberta por outras pessoas de que seu familiar adolescente é um usuário de drogas, demonstrando com isso sentimento de proteção do mesmo em não se expor:

Eu não quis contar para minha família, não quis contar para minha nora, esposa do meu filho mais velho. Não quis contar nem para minha nora porque eu tinha medo que as pessoas soubessem, ai me aconselharam a contar para minha irmã, que me deu muita força para internar ela em uma clinica. Tem umas pessoas que jogam umas coisas para você, que dão umas picadinhas que são as amigas entre aspas, eu já passei por isso, depois que ela começou a usar drogas, as pessoas jogam na minha cara eu não tenho filha noia entendeu? Eu continuo só por Deus, e a palavra de Deus. (E5)

0 sofrimento vivenciado por esses familiares é tão grande, como podemos ver nos relatos a seguir 0 desânimo a desesperança 0 sentimento de derrota $e$ tristeza são visíveis, fazendo com que o familiar queira desistir de ajudar no tratamento e cura do adolescente usuário de drogas.

Eu sempre penso em desistir, já pensei em me enfiar em algum lugar e sumir, tem dia que eu tenho vontade de abrir um buraco no chão, e sumir, tem dia que eu tenho vontade de pedir para Deus me recolher, e eu falo para eles, vou pedir para Deus me recolher e vocês vão se virar do jeito que vocês querem, se lasquem ou vão melhorar sem mim. Eu falo para ele se ele se enfiar mais nessa vida nem futuro ele vai ter mais, ele dá a impressão que não está nem ai, entra por um ouvido e sai pelo outro é igual o mais velho. (E1)

Eu já cheguei a pensar em desistir, sabe, mas a gente tenta conversar, tenta explicar, às vezes brigo, eu me altero com ele sabe, mas 
às vezes eu chamo senta aqui do meu lado vamos conversar explico. Eu acho que ele não pensa em mudar essa vida, daqui a pouco ele tá fazendo tudo de novo. (E4)

Buscando sobreviver, com as incertezas, a família sofre várias consequências, que refletem diretamente no ambiente familiar como um todo. Com isso, os membros da família vivenciam um constante sofrimento e desespero que transformam a sua vida, tanto familiar quanto social, que provocam consequências físicas, psicológicas, emocionais, financeiras, entre outras (SIQUEIRA et al., 2012).

Outro sentimento vivenciado pelas entrevistas foi a fé que esteve presente na maioria das entrevistadas, demonstrando que é por meio dela que as mantêm firmes e fortes para suportar as dificuldades enfrentadas até então:

Tem hora que eu caio viu! Mas eu falo meu Deus me levanta, me segura, porque Deus que me mantêm me segura, se não fosse Deus na minha vida a minha fé, eu não teria aguentado de jeito nenhum. Eu tenho essa cruz na minha vida. Eu não choro perto deles porque eu sei que esse problema deles é muito difícil, eu falo porque vocês entraram em numa coisa tão difícil, e eu choro sozinha eu e Deus e eu fico com meu sofrimento sozinha e quando converso com alguém eu não aguento. Eu descarrego na igreja, ali eu rezo eu choro. É muito triste, viu, só quem tá passando sabe o quanto a dor é grande, muitas mães eu vejo, que não é só eu que estou passando por isso e umas não aguentam até morrem. Quando meus fiIhos saem eu fico agoniada com o coração na mão, desesperada, enquanto eles não chegam, enquanto não estão dentro de casa eu vou deitar eu dobro os meus joelhos e agradeço a Deus por estar todos juntos em casa, então é desse jeito a minha vida, demora um pouquinho a mais na rua 0 meu caçula eu fico desesperada, fico ligando e mando ele vir embora. (E1)
Eu ainda tenho muita força de vontade, quando eu tenho que chorar eu choro nos pés do Senhor, é nos pés do Senhor, não adianta contar para um, contar para outro, não é sempre que você encontra alguém para se abrir, quando você mais precisa, você não encontra. (E5)

Segundo Siqueira et al. (2012), são vários os elementos que contribuem para a continuidade, ou não, da luta pela sobrevivência do familiar usuário de drogas bem como a manutenção da própria estrutura familiar. Pode-se dizer que alguns elementos contribuíram de forma benéfica, ou seja, que proporcionaram a composição necessária para a família seguir em frente, com fé em Deus. Nota-se que a religiosidade, a inserção em grupos de apoio, a terapia com especialistas e outros constituem-se em fatores favoráveis para auxiliar no processo de enfrentamento da desordem e insegurança.

\section{CONSIDERAÇÕES FINAIS}

0 uso crescente das drogas por adolescentes no Brasil vem se tornando um problema de saúde pública, poucas ações estão sendo feitas para que diminua esse número crescente. Com isso, as consequências dos usos das drogas refletem na vida do adolescente consequentemente afetando também a vida de seus familiares, que precisam abdicar de suas vidas e afazeres para conseguir acompanhar seu familiar adolescente em seu tratamento.

Para que ocorra a redução do consumo das drogas entre adolescentes é preciso que as autoridades educacionais e sanitárias trabalhem em conjunto com a rede de assistência, desenvolvendo ações para prevenção e promoção aos usuários de substâncias químicas em idade precoce. É necessário também reforçar a vigilância para exigir o cumprimento da lei, em relação à proibição da venda de cigarro e bebidas aos menores de 18 anos. Deve haver um planejamento a fim de informar sobre as consequências dos usos das drogas. 
Portanto, para se criar uma ação voltada ao uso de substâncias psicoativas em adolescentes, é preciso contar com a ajuda dos familiares, reforçando seus vínculos e contribuir para que os pais adotem posturas benéficas e eficientes com seus filhos, favorecendo a socialização, para poder produzir resultados mais eficazes. Mostrar para os pais que eles são os principais responsáveis pela consolidação de crenças, e valores contrários a comportamentos prejudiciais à saúde e ao desenvolvimento mental de seus filhos.

Em consequência a isso, muitos sentimentos são despertados nos familiares, como a negação, raiva, tristeza, desesperança entre outros por ter perdido seu familiar adolescente para o "mundo" das drogas.

Entretanto, 0 que foi possível observar no estudo realizado, por meio dos relados dos familiares, que mesmo com as dificuldades enfrentadas, com a sobrecarga de serviços, tarefas e sentimentos, a vontade de ajudar seu familiar usuário de drogas ainda é grande, muitos deles se apoiam na religião como uma forma de se manter forte.

Diante disso surge a necessidade de uma atenção voltada ao familiar do adolescente usuário de drogas nos serviços de saúde, uma forma de apoiar esses familiares para que consigam lidar com as necessidades de seus familiares adolescente usuário de drogas que passam por inúmeras dificuldades durante 0 tratamento e recuperação. Para então melhorar a qualidade de vida desses familiares.

\section{REFERÊNCIAS}

ALVES, R; KOSSOBUDZKY, L. A. Caracterização dos adolescentes internados por álcool e outras drogas na cidade de Curitiba. Interação em Psicol, Curitiba, v. 1, n. 6, p.65-79, 2002. Disponível em: <http://revistas. ufpr.br/psicologia/article/view/3195/2558>. Acesso em: 07 nov. 2015.

BRASIL. Lei $n^{0}$ 8.069, de 13 de julho de 1990. Dispõe sobre o Estatuto da Criança e do Adolescente e dá outras providências. Diário Oficial [da] República Federativa do Brasil, Brasília, DF, 16 jul. 1990.
BRASIL. Ministério da Saúde. Saúde mental no sus: os centros de atenção psicossocial. Brasília, 2004, 86 p.

BRUSAMARELLO, T. et al. Papel da família e da escola na prevenção do uso de drogas pelo adolescente estudante. Cienc Cuid Saúde, Maringá, v.9, n.4, p.766-773, out/dez. 2010. Disponível em: <http:// periodicos.uem.br/ojs/index.php/CiencCuidSaude/ article/view/13828>. Acesso em: 15 mar. 2015.

CARVALHO, S. M. C; OLIVEIRA, S. B. A; MARTINS, S. M. L. R. Interd, 2014. v. 7, n. 3, p. 121-130. Disponível em: $\quad<$ http://revistainterdisciplinar.uninovafapi.edu. br/index.php/revinter/article/viewFile/318/pdf_145>. Acesso em: 15 mar. 2015.

CANAVEZ, F. M; ALVES, R. A; CANAVEZ, S. L. Fatores predisponentes para o uso precoce de drogas por adolescentes. Cadernos UniFOA, Volta Redonda, dez. 2010. n.14, . Disponível em: <http://web.unifoa.edu. br/cadernos/edicao/14/57.pdf>. Acesso em: 26 mar. 2015.

GIL, A. C. Como elaborar projetos de pesquisa. 4. ed. São Paulo: Atlas, 2009.

JINEZ, M. L. J; SOUZA, J. R. M; PILLON, S. C. Uso de drogas e fatores de risco entre estudantes de ensino médio. Rev. Latino-Am Enfermagem, São Paulo, v. 2, n. 17, p. 246-252, abr. 2009. Disponível em: <http:// www.revistas.usp.br/rlae/article/view/2568/3166>. Acesso em: 7 nov. 2015.

MARQUES, A. C. P. R; CRUZ, M. S. 0 adolescente e 0 uso de drogas. Rev. Bras. Psiquiatr., São Paulo, dez. 2000. v.22, supl.2, p. 32-36. Disponível em: $<$ http://www.scielo.br/scielo.php?pid=S151644462000000600009\&script=sci_arttext $>$. Acesso em: 15 mar. 2015.

MINAYO, M. C. S. 0 desafio do conhecimento: pesquisa qualitativa em saúde. 10. ed. São Paulo: Hucitec, 2007.

PESSALACIA, J. D. R; MENEZES, E. S.; MASSUIA, D. A. vulnerabilidade do adolescente numa perspectiva 
das políticas de saúde pública. Revista Bioethikos, São Camilo, v. 4, n. 4, p.423-430, 2010. Disponível em: <http://www.saocamilo-sp.br/pdf/bioethikos/80/ Bioethikos_423-430_.pdf >.Acesso em: 07 nov. 2015.

PINSK, I.; BESSA, M. A. Adolescência e drogas. 3. ed. São Paulo: Contexto, 2004.

REIS, H. F. T; MOREIRA, T. 0.0 crack no contexto familiar: uma abordagem fenomenológica. Texto contexto - enferm., Florianópolis, v. 22, n. 4, p. 1115-1123, dez. 2013. Disponível em: <http://www. scielo.br/scielo.php?script=sci_arttext\&pid=S010407072013000400030\&lng=en\&nrm=is0 >. Acesso em: 24 mar. 2015.

SELEGHIM, R. M; OLIVEIRA, F. L. M. Influência do ambiente familiar no consumo de crack em usuários. Acta Paul Enferm, São Paulo, v.26, n.3, p 263-268, 2013. Disponível em: <http://www.scielo.br/pdf/ape/ v26n3/10.pdf >. Acesso em: 26 mar. 2015.

SIQUEIRA, et al. Repercussões do uso de crack no cotidiano da família. Cogitare Enferm.; Curitiba, v.17, n.2, p.248-254, abr./jun. 2012. Disponível em: <http://ojs.c3sl.ufpr.br/ojs/index.php/cogitare/article/ view/23518/18465>. Acesso em: 15 mar. 2015.

SILVA, B. L. C. etal. Participação da família no tratamento dos usuários do centro de atenção psicossocial de álcool e outras drogas. Rev. Bras. Pesq. Saúde, Vitória, v. 4, n. 14, p.61-68, 2012. Disponível em: <https:// scholar.google.com.br/scholar?q=Participação+da+f amília+no+tratamento+dos+usuários+do+centro+de +atenção+psicossocial+de+álcool+e+outras+drogas $\& b t n G ;=\& h l=p t-B R \& a s \_s d t=0,5 \& a s \_v i s=1>$. Acesso em: 7 nov. 2015.

SILVA, V. A.; MATTOS, H. F. Os jovens são mais vulneráveis as drogas? In: PINSK, I.; BESSA, M. A. Adolescência e drogas. 3. ed. São Paulo: Contexto, 2004.

TAVARES, B. F; BÉRIA, J. U; LIMA, M. S. Prevalência do uso de drogas e desempenho escolar entre adolescentes. Rev. Saúde Pública, São Paulo, v. 2, n. 35, p.150-158, 2001. Disponível em: <http://www. scielo.br/pdf/rsp/v35n2/4399.pdf>. Acesso em: 07 nov. 2015.

ZACHARIAS, D. G. et al. Familiares de usuários do crack: da descoberta aos motivos para o uso da droga. In: JORNADA DE PESQUISA EM PSICOLOGIA, 4., 2011, Santa Cruz do Sul. Anais eletrônicos... Santa Cruz do Sul: Unisc, 2011. p. 16-29. Disponível em: <http:// online.unisc.br/acadnet/anais/index.php/jornada_ psicologia/article/view/10184/5>. Acesso em: 15 mar. 2015.

Recebido em: 17 de maio de 2016 Aceito em: 19 de setembro de 2016 